\title{
Enhancing Moisture and Water Resistance in Perovskite Solar Cells by Encapsulation with Ultrathin Plasma Polymers
}

Jesús Idígoras ${ }^{a, *}$, Francisco J. Aparicio $^{b}$, Lidia Contreras-Bernal ${ }^{a}$, Susana Ramos-Terrón ${ }^{a}$, María Alcaire ${ }^{b}$, Juan Ramón. Sánchez-Valencia ${ }^{b}$, Ana Borras ${ }^{b}$, Ángel Barranco ${ }^{b, *}$, Juan A. Anta $^{a, *}$

a Área de Química Física, Universidad Pablo de Olavide, Seville, E-41013, Spain.

${ }^{\mathrm{b}}$ Instituto de Ciencia de Materiales de Sevilla (CSIC-Universidad de Sevilla), Seville, E-41092, Spain

Keywords: perovskite, moisture, encapsulation, polymer, vacuum plasma deposition.

Supporting Information. Chemical structure of adamantane. Schematic of controlled humid conditions system. Digital photographs of reference and encapsulated devices submitted to different degradations tests.

\begin{abstract}
A compromise between high power conversion efficiency and long-term stability of hybrid organic-inorganic metal halide perovskite solar cells is necessary for their outdoor photovoltaic application and commercialization. Herein, a method to improve the stability of perovskite solar
\end{abstract}


cells under water and moisture exposure consisting in the encapsulation of the cell with an ultrathin plasma polymer is reported. The deposition of the polymer is carried out at room temperature by the remote plasma vacuum deposition of adamantane powder. This encapsulation method does not affect the photovoltaic performance of the tested devices and is virtually compatible with any device configuration independently of the chemical composition. After 30 days under ambient conditions with a relative humidity in the $35 \%-60 \%$ range, the absorbance of encapsulated perovskite films remains practically unaltered. More impressively, when encapsulated solar devices were immersed in water, the photovoltaic performance was not affected at least within the first 60 seconds. In fact, it has been possible to measure the power conversion efficiency of encapsulated devices under operation in water. The proposed method opens up a new promising strategy to develop stable photovoltaic and photocatalytic perovskite devices.

\section{Introduction}

Due to the excellent optoelectronic properties of hybrid organic-inorganic metal halide perovskites, ${ }^{1-4}$ the photovoltaic field has undergone a rapid progress in the last decade. Perovskites were first introduced in the field as sensitizers in dye-sensitized solar cells with promising results but very poor stability due to dissolution of the perovskite in the liquid electrolyte. ${ }^{5}$ Stability and efficiency was dramatically improved by introducing a solid-state hole conductor and a mesoporous $\mathrm{TiO} 2 /$ perovskite layer. ${ }^{6,7}$ Currently, the certified power conversion efficiency of perovskites solar cells $(22.1 \%)^{8}$ is comparable to the photovoltaic performance of other thin-film photovoltaic technologies ( $\mathrm{Si}, \mathrm{CdTe}, \mathrm{GaAs})$. Nevertheless, in spite of this progress, the poor-term stability of photovoltaic perovskite complicates their commercialization. 
Degradation processes in these devices are not only related to the intrinsic properties that determine the thermal and/or electrical stability (device configuration and perovskite composition), ${ }^{9,10}$ but also it is strongly affected by environmental factors (moisture, light, oxygen and temperature). ${ }^{11,12}$ Specifically, under moisture exposure, as a consequence of, mainly, the reaction between water molecules and methylammonium cations $\left(\mathrm{CH}_{3} \mathrm{NH}_{3}{ }^{+}\right)$which acts as a Brønsted/Lewis base, the perovskite tend to be hydrolyzed back to the precursors giving rise to morphological and crystal structural changes, optical absorption decay and the deterioration of the electronic properties that determine the photovoltaic performance of perovskite solar cells. ${ }^{13-}$ 15

Different strategies have been employed to prevent the degradation and improve the device stability due to the sensitivity of perovskite materials towards ambient moisture. Many of them imply the modification of the perovskite composition by the insertion of ions to achieve a more stable crystal structure, ${ }^{9}$ the addition of water soluble polymer in the perovskite precursor solution, ${ }^{16}$ the employment of buffer layers between perovskite films and electron or hole selective layers ${ }^{17-19}$ or even the substitution of the Spiro-OMeTAD layer by other more hydrophobic hole selective material ${ }^{20-22}$. On the other hand, different materials have also been employed to encapsulate complete perovskite solar devices and avoid moisture exposure. This is the case of carbon nanotubes, ${ }^{23}$ hydrophobic polymer ${ }^{24}$, atomic layer deposited $\mathrm{Al}_{2} \mathrm{O}_{3}$ films ${ }^{25}$ or even using sealing glass as barrier layer. ${ }^{26}$ Nevertheless, the greatest breakthrough in terms of stability has recently been achieved by engineering an ultra-stable $2 \mathrm{D} / 3 \mathrm{D}$ perovskite junction. ${ }^{27}$ Although successfully, many of these approaches involve expensive and complex deposition processes and even restrict the photovoltaic performance of perovskite solar devices. 
Here, we investigate a simple solvent-free polymer encapsulation method for perovskite solar cells using a conformal plasma polymer thin film. This organic layer is formed by the remote plasma assisted vacuum deposition of the solid precursor adamantane (ADA). The synthesis is carried out at room temperature and under a low power plasma activation to avoid energetic species or UV radiation of the plasma to reach the substrate surface. This methodology has been successfully applied in recent articles for the fabrication of photonics films based on organic dyes and small functional molecules working as optical sensors, optical filters, tunable photoluminescence emitters and lasing gain media. ${ }^{28-31}$ This deposition process is compatible with opto- and micro-electronics components and can be scaled to large deposition areas and to wafer scale fabrication. ${ }^{32,33}$ To our best knowledge, this is the first report where the deposition of an organic plasma nanocomposite thin film is employed to encapsulate perovskite solar cells. The ADA precursor molecules $\left(\mathrm{C}_{10} \mathrm{H}_{16}\right)$ consist of single $\mathrm{C}-\mathrm{C}$ bonds with four connected cyclohexane rings arranged in the armchair configuration (Scheme S1 in the Supporting Information section). This material is very effectively plasma polymerized under remote conditions allowing the deposition of homogenous and compact ADA thin films characterized for being insoluble in water and thermally stable up to $250{ }^{\circ} \mathrm{C}$. Additionally, these deposited films show a high transmittance $(\approx 90 \%)$ in the low-energy region of the visible spectrum $(\lambda>$ $300 \mathrm{~nm})^{30,34}$

\section{Experimental Section}

\subsection{Fabrication of perovskite solar cells}

Perovskite solar cells were fabricated on FTO-coated glass (Pilkington-TEC15) patterned by laser etching. Before use, the substrates were cleaned using Hellmanex ${ }^{\circledR}$ solution and rinsed with 
deionized water and ethanol. Thereupon, they were ultrasonicated in 2-propanol and dried by using compressed air. The $\mathrm{TiO}_{2}$ blocking layer was deposited onto the substrates by spray pyrolysis at $450{ }^{\circ} \mathrm{C}$, using a titanium diisopropoxide bis(acetylacetonate) solution (75\% in 2 propanol, Sigma Aldrich) diluted in ethanol (1:3.5, v/v), with oxygen as carrier gas. The $\mathrm{TiO}_{2}$ compact layer was then kept at $450{ }^{\circ} \mathrm{C}$ for $30 \mathrm{~min}$ for the formation of anatase phase. Once the samples achieve room temperature, a $\mathrm{TiO}_{2}$ mesoporous layer was deposited by spin coating at $2000 \mathrm{rpm}$ during $10 \mathrm{~s}$ using a commercial $\mathrm{TiO}_{2}$ paste (Dyesol, 30NRD) diluted in ethanol (1:5, weight ratio). After drying at $100{ }^{\circ} \mathrm{C}$ for $10 \mathrm{~min}$, the $\mathrm{TiO}_{2}$ mesoporous layer was heated at 500 ${ }^{\circ} \mathrm{C}$ for $30 \mathrm{~min}$ and later cooled to room temperature. Subsequently, a pure methylammonium $\left(\mathrm{MAPbI}_{3}\right)$ solution were prepared to be deposited by spin coating using a methodology recently reported. ${ }^{35}$ Then, Spiro-OMeTAD was deposited as hole selective material by dissolving 72.3 $\mathrm{mg}$ in $1 \mathrm{~mL}$ of chlorobenzene as well as $17.5 \mu \mathrm{L}$ of a lithium bis (trifluoromethylsulphonyl)imide (LiTFSI) stock solution (520 $\mathrm{mg}$ of LiTFSI in $1 \mathrm{~mL}$ of acetonitrile), and $28.8 \mu \mathrm{L}$ of 4 -tertbutylpyridine (TBP). The Spiro-OMeTAD was spin coated at $4000 \mathrm{rpm}$ for $30 \mathrm{~s}$. Finally, $60 \mathrm{~nm}$ of gold was deposited as a metallic contact by thermal evaporation under a vacuum level between $1 \cdot 10^{-6}$ and $1 \cdot 10^{-5}$ torr. All the deposition processes were carried out outside the glovebox under environmental conditions.

\subsection{Deposition of adamantane nanocomposite thin film}

The encapsulation process was carried out in a microwave plasma reactor, detailed elsewhere, ${ }^{29,36}$ which was pumped down to base pressure of $10^{-6}$ torr before and after deposition. The deposition system consists of an electron cyclotron resonance (ECR) plasma reactor with two separated zones for plasma and remote deposition. In the plasma zone, an argon microwave plasma (power $150 \mathrm{~W}$ and pressure $10^{-2}$ torr) is sustained and confined thanks to a set of 
magnets. The substrate holder, a thin metallic grid, is placed in a downstream configuration at a distance $\mathrm{z}=9.5 \mathrm{~cm}$ from the glow discharge, according the scheme included in reference. ${ }^{36}$ The samples were fixed to the back side of the holder where they are not directly exposed to the remote plasma discharge. A scheme of this geometrical arrangement is included in the supporting information of reference, ${ }^{29}$ there the configuration used in the present investigation is referred to as "back". Adamantane (Scheme S1) powder from Sigma-Aldrich was used as precursor. The precursor supply system includes an external glass ampoule which is heated during the deposition process in order to dose a given vapor pressure of this monomer into the system.

\subsection{Characterization of films and devices}

Current-voltage curves were measured under a solar simulator (ABET-Sun2000) with an AM 1.5G filter. The light intensity was calibrated at $100 \mathrm{~mW} \cdot \mathrm{cm}^{-2}$ using reference mono-crystalline silicon solar cell with temperature output (ORIEL, 91150). A metal mask was used to define an active area of $0.16 \mathrm{~cm}^{2}$. The current-voltage curves were obtained in reverse scan using a scan rate of $100 \mathrm{mV} \cdot \mathrm{s}^{-1}$ and sweep delay of $20 \mathrm{~s}$. For current-voltage curves of encapsulated devices immersed in water, a white-LED was used as illumination source.

For optical characterization, UV-Visible absorption spectra were recorded by using a Cary 100 $\mathrm{UV}-\mathrm{Vis}$ spectrophotometer (Agilent) in the range of $400-850 \mathrm{~nm}$. For structural characterization, Scanning Electron Microscope (SEM) images of the samples were performed using a Zeiss GeminiSEM-300 microscope working at $2 \mathrm{KeV}$. Water contact angles measurements were performed depositing $5 \mu \mathrm{L}$ drop of distilled water on the surface. For structural characterization, X-ray diffractograms were acquired in a Panalytical X'PERT PRO instrument in the BraggBrentano configuration. 


\section{Results and Discussion}

The mesoporous-perovskite device configuration has been employed in this work to analyze the potential of the ADA nanocomposite thin film as barrier layer for the encapsulation of solar cells. For this device configuration, a $\mathrm{TiO}_{2}$ mesoporous layer $\left(m \mathrm{TiO}_{2}\right)$ deposited onto a $\mathrm{TiO}_{2}$ compact layer $\left(c \mathrm{TiO}_{2}\right)$ and a Spiro-OMeTAD layer were employed as electron and hole selective materials, respectively. $\mathrm{A} \mathrm{CH}_{3} \mathrm{NH}_{3} \mathrm{PbI}_{3}$ film (MAPI) deposited under a relative humidity of 35\% was employed as photoactive material according to a recent report. ${ }^{35}$ The encapsulation of the solar cells was carried out by remote plasma assisted deposition of ADA nanocomposite films with a thickness ca. $200 \mathrm{~nm}$ (see Supporting Information section for further experimental details) (Figure $1 \mathrm{~A}$ and S1). 


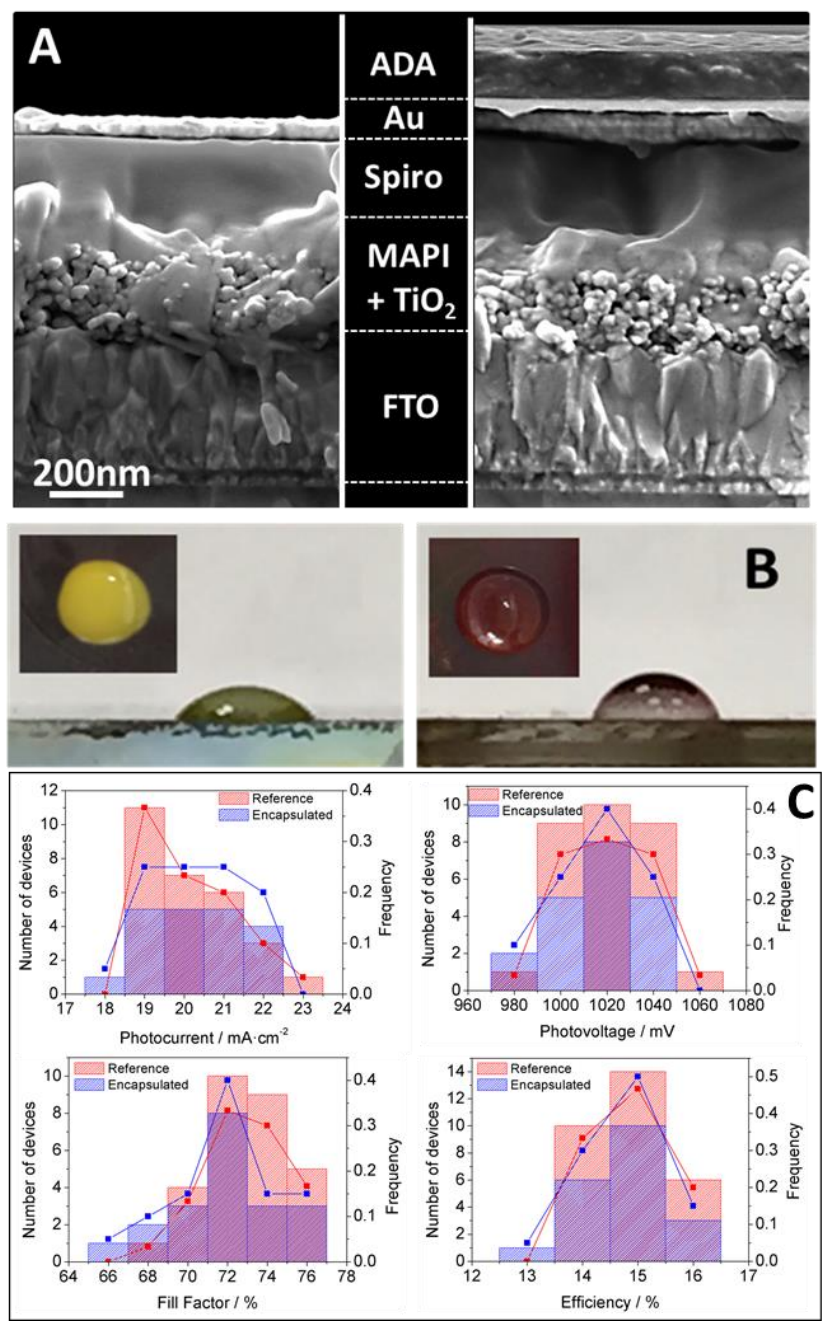

Figure 1. (A) Cross-sectional SEM images of reference $\left(\mathrm{FTO} / c \mathrm{TiO}_{2} / m \mathrm{TiO}_{2} / \mathrm{MAPI} / \mathrm{Spiro-OMeTAD} / \mathrm{Au}\right)$ and encapsulated $\left(\mathrm{FTO} / \mathrm{TiO}_{2} / m \mathrm{TiO}_{2} / \mathrm{MAPI} /\right.$ Spiro-OMeTAD/Au/ADA) devices. (B) Digital photograph of both devices showing contact angles - Note the insets showing the water drop on surface that evidence the different colorations. (C) Photovoltaic parameters statistics in terms of number of samples and frequency for reference (30 samples) and encapsulated (20 samples) devices under 1 sun - AM 1.5 illumination in reverse scan with a scan rate of $100 \mathrm{mV} \cdot \mathrm{s}^{-1}$.

The low affinity to water of the ADA layer was determined by static water contact angle (WCA) measurements. Water contact angles depend on both chemical composition and 
roughness of the surface, with hydrophobic/hydrophilic materials depicting WCA higher/lower than $90^{\circ} .{ }^{37}$ Water angle contacts of $46^{\circ}$ and $82^{\circ}$ were obtained when the droplet was deposited on top of the Spiro-OMeTAD layer and ADA thin film for reference and encapsulated devices, respectively (Figure 1B). In this case, the apparent contact angle value for the ADA layer deposited on the solar cell is slightly lower than $90^{\circ}$ corresponding to a partially hydrophobic surface. In contrast, Spiro-OMeTAD presents a hydrophilic behavior. On the other hand, the deposition method consists in a room temperature free-solvent process that provides fully conformal and transparent layers without stressing or damaging the interface with the support or substrate. The growth of the ADA film is assisted by a microwave plasma in a downstream configuration, i.e. out of the glow discharge, which ensures the compatibility with the deposition on thermal-sensitive and delicate materials..$^{29,30}$ Therefore, considering the hydrophobic behavior of ADA material, the blocking of water diffusion through ADA thin film towards underlying layers could be attributed to the formation of an extremely compact, conformal and defect-free (for instance cracks, voids and grain borders) film. These are critical advantages from the point of view of the device encapsulation as evidenced by comparison of the insets in Figure 1B. Thus, the droplet on the ADA surface does not turn yellow in contrast to the drop on the reference surface. The yellowish color is due to $\mathrm{PbI}_{2}$ solution in the water droplet and it can only be attributed to the diffusion of water molecules through Spiro-OMeTAD layer and, consequently, to the perovskite degradation, ${ }^{15,24}$ The contact angle results together with the blocking of water diffusion make evident the favorable chemical properties of ADA molecules to protect the active film of the perovskite solar cell against environmental moisture. 
To rule out that the deposition of ADA thin film affects the photovoltaic performance of perovskite solar cells and to confirm that the gold layer still makes good contact, current-voltage curves were measured for both reference and encapsulated devices (Figure 1C). In fact, no significant change was observed in the power energy conversion efficiency for the two device configurations. In particular, average photovoltaic performances of $14.8 \%$ and $14.7 \%$ were achieved under $100 \mathrm{~mW} \cdot \mathrm{cm}^{-2}$ simulated AM $1.5 \mathrm{G}$ irradiation for reference $\left(J_{S C}: 19.9 \mathrm{~mA} \cdot \mathrm{cm}^{-2}\right.$, $V_{O C}: 1020 \mathrm{mV}$, Fill Factor: 0.73) and encapsulated $\left(J_{S C}: 20.1 \mathrm{~mA} \cdot \mathrm{cm}^{-2}, V_{O C}: 1015 \mathrm{mV}\right.$, Fill Factor:.72) devices. Therefore, the deposition of ADA thin film does not produce any detrimental effect on the processes and/or properties that determine the photovoltaic
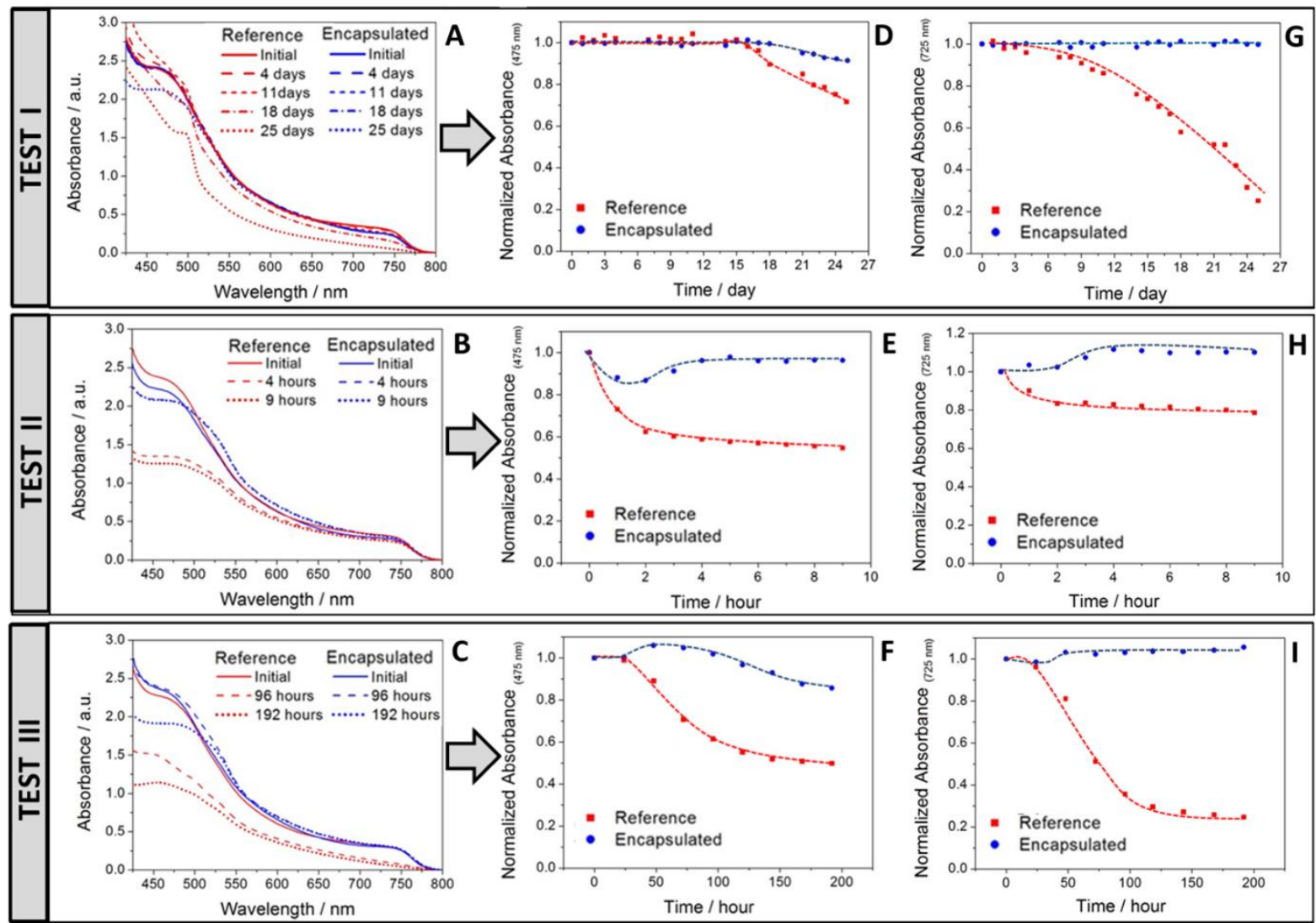

performance.

Figure 2. (A, B, C) Absorption spectra and normalized absorbance kinetics at (D, E, F) $475 \mathrm{~nm}$ and at (G, $\mathrm{H}$, I) $725 \mathrm{~nm}$ of reference (glass $/ m \mathrm{TiO}_{2} / \mathrm{MAPI} / \mathrm{HSL}$ ) and encapsulated (glass $/ m \mathrm{TiO}_{2} / \mathrm{MAPI} / \mathrm{HSL} / \mathrm{ADA}$ ) 
samples before and after different moisture exposure times and conditions: (A, D, G) Test I - under environmental conditions $(35 \%<\mathrm{RH}<60 \%)$ and darkness, (B, E, H) Test II - under air flow with a RH $>85 \%$ in darkness and $(\mathrm{C}, \mathrm{F}, \mathrm{I})$ Test III - under environmental conditions $(35 \%<\mathrm{RH}<60 \%)$ and illumination.

Since it is well-known that environmental conditions affect mainly the perovskite active layer of the solar cells devices, the efficacy of ADA thin film as encapsulation method was investigated by analyzing the optical properties of reference and encapsulated perovskites films. ${ }^{38,39}$ This was done by looking at the changes of absorption spectra with respect to moisture exposure time. For this, three different stability tests were devised. Figure 2 shows the UV-Vis absorption spectra and decay kinetics for reference (glass $/ m \mathrm{TiO}_{2} / \mathrm{MAPI} / \mathrm{HSL}$ ) and encapsulated (glass $/ m \mathrm{TiO}_{2} / \mathrm{MAPI} / \mathrm{HSL} / \mathrm{ADA}$ ) perovskite under different environmental conditions (relative humidity and illumination) at room temperature. Considering the absorption spectra of $\mathrm{PbI}_{2},{ }^{24}$ the decay kinetics was analyzed at $475 \mathrm{~nm}$ and $725 \mathrm{~nm}$. In all cases, slower decay kinetics was observed for encapsulated devices. When samples were stored in darkness under environmental moisture with a relative humidity in the range of $35 \%-60 \%$ (Test I), the absorbance of encapsulated samples remains almost unaffected even after 25 days (Figure 2A). In contrast, the absorbance of references samples does not only decrease but also changes its wavelength dependence. For longer moisture exposure times, the characteristic peak at $500 \mathrm{~nm}$ attributed to the formation of $\mathrm{PbI}_{2}$ is more marked which is brought to light with a color change from brown to yellow ${ }^{21}$ (Supporting Information, Figure S1). Although the absorbance kinetics at $425 \mathrm{~nm}$ for both reference and encapsulated samples is similar during the first 15 days (Figure 2D), the fact is that after that reference devices decay faster after that time. This rapid degradation of reference devices in Test $\mathrm{I}$ is more visible at $725 \mathrm{~nm}$ (Figure 2G). When the samples were exposed to 
higher values of moisture ( $\mathrm{RH}>85 \%)$ in darkness (Test II), a significant absorbance decay was only observed for reference samples (Figure 2B). In this case, the relative humidity was controlled by adjusting the flow of vapor carrier gas and employing a relative humidity sensor to control the RH level (Supporting Information, Scheme S2). After 9 hours in these extreme conditions, absorbance decays of $40 \%$ and $20 \%$, at $425 \mathrm{~nm}$ and $725 \mathrm{~nm}$ respectively, were observed for reference samples just after 2 hours of moisture exposure. In spite of these results, an absorbance decay was detected for both reference and encapsulated devices when were exposed under environmental moisture and illumination (Test III - Figure 2C). The impact of the coupled effect of moisture and illumination on the perovskite stability gives rise to a more severe and faster degradation processes. ${ }^{39}$ Nevertheless, encapsulated devices show clearly slower degradation kinetics (Figure 2H and 2I). It is worth of noting how, after 192 hours, the absorbance of the reference sample has lost more than $50 \%$ of his absorption capacity displaying the characteristic yellowish coloration of a fully degraded perovskite. In contrast, encapsulated samples preserve their original brownish coloration (Supporting Information, Figure S1). Nonetheless, some yellow spots emerge at the top of the sample. This can be attributed to water infiltration through surface defects located at the device edge, which is a technical issue that can be easily solved by further developments. All these tests demonstrate that the deposition of ADA thin film as encapsulation method effectively avoids the perovskite moisture-induced degradation processes improving the perovskite stability. 

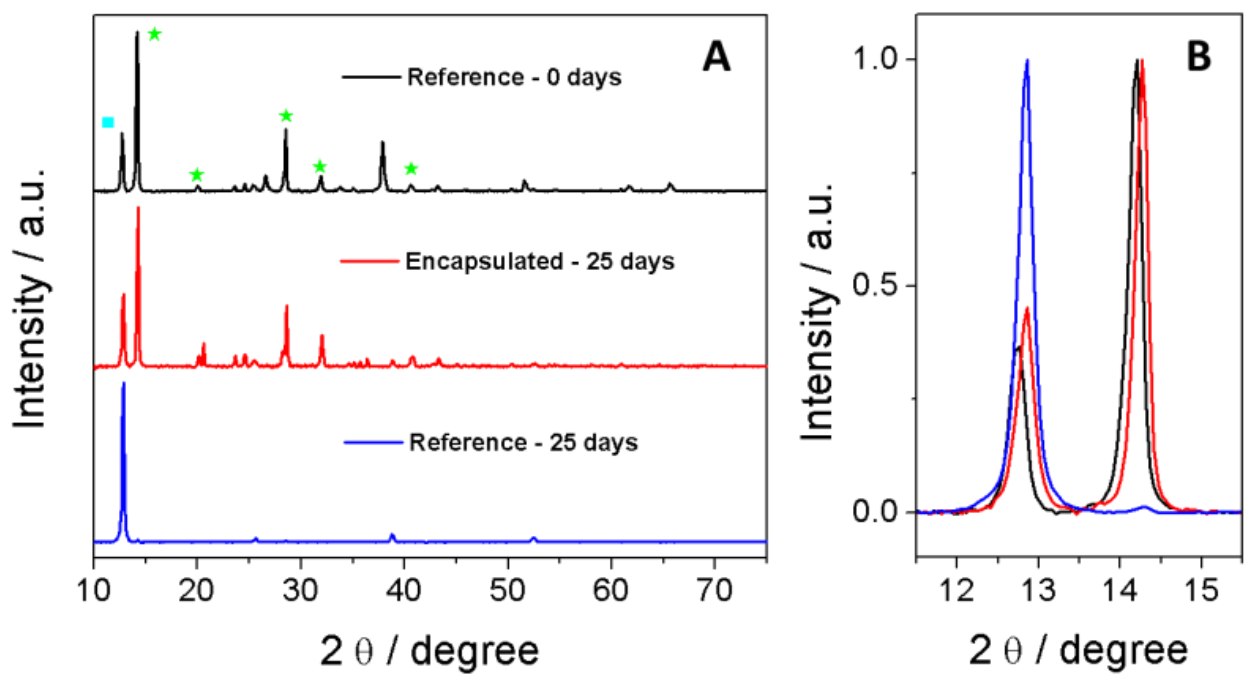

Figure 3. (A) X-Ray diffraction of a reference and encapsulated samples after 25 days of exposure to environmental moisture $(35 \%<\mathrm{RH}<60 \%)$ in darkness and a non-treated reference sample. The $\mathrm{CH}_{3} \mathrm{NH}_{3} \mathrm{PbI}_{3}$ perovskite peaks are labelled with green starts. The cyan square corresponds to $\mathrm{PbI}_{2}$. (B) Enlarged view of the $\mathrm{PbI}_{2}$ and the main perovskite peaks after normalization at the maximum intensity.

In order to confirm the ability of this encapsulation method, the XRD patterns of reference and encapsulated devices exposed to a prolonged moisture exposure $(35 \%<\mathrm{RH}<60 \%$ - Test I) are shown in Figure 3. The pattern of the freshly synthetized perovskite layer was also included for comparison. The spectrum of this latter shows the characteristic XRD peaks of the $\mathrm{CH}_{3} \mathrm{NH}_{3} \mathrm{PbI}_{3}$ perovskite at $14.1^{\circ}, 20.0^{\circ}, 28.5^{\circ}, 31.9^{\circ}$, and $40.6^{\circ}$ alongside the $\mathrm{PbI}_{2}$ diffraction peak at $12.7^{\circ} .^{40,41,14}$ After prolonged moisture exposure (25 days), this latter feature is the only one observed for reference devices, which indicates the whole degradation of the $\mathrm{CH}_{3} \mathrm{NH}_{3} \mathrm{PbI}_{3}$ perovskite phase into $\mathrm{PbI}_{2}$. On the contrary, the perovskite diffraction peaks are preserved in the encapsulated sample. Figure 3B compares the relative diffraction intensities of perovskite and $\mathrm{PbI}_{2}$ for the three samples in more detail showing just a rather negligible increase in the $\mathrm{PbI}_{2}$ 
peak for the encapsulated sample after the 25 days of exposure. These results confirm the efficacy of the ADA film as moisture barrier layer.
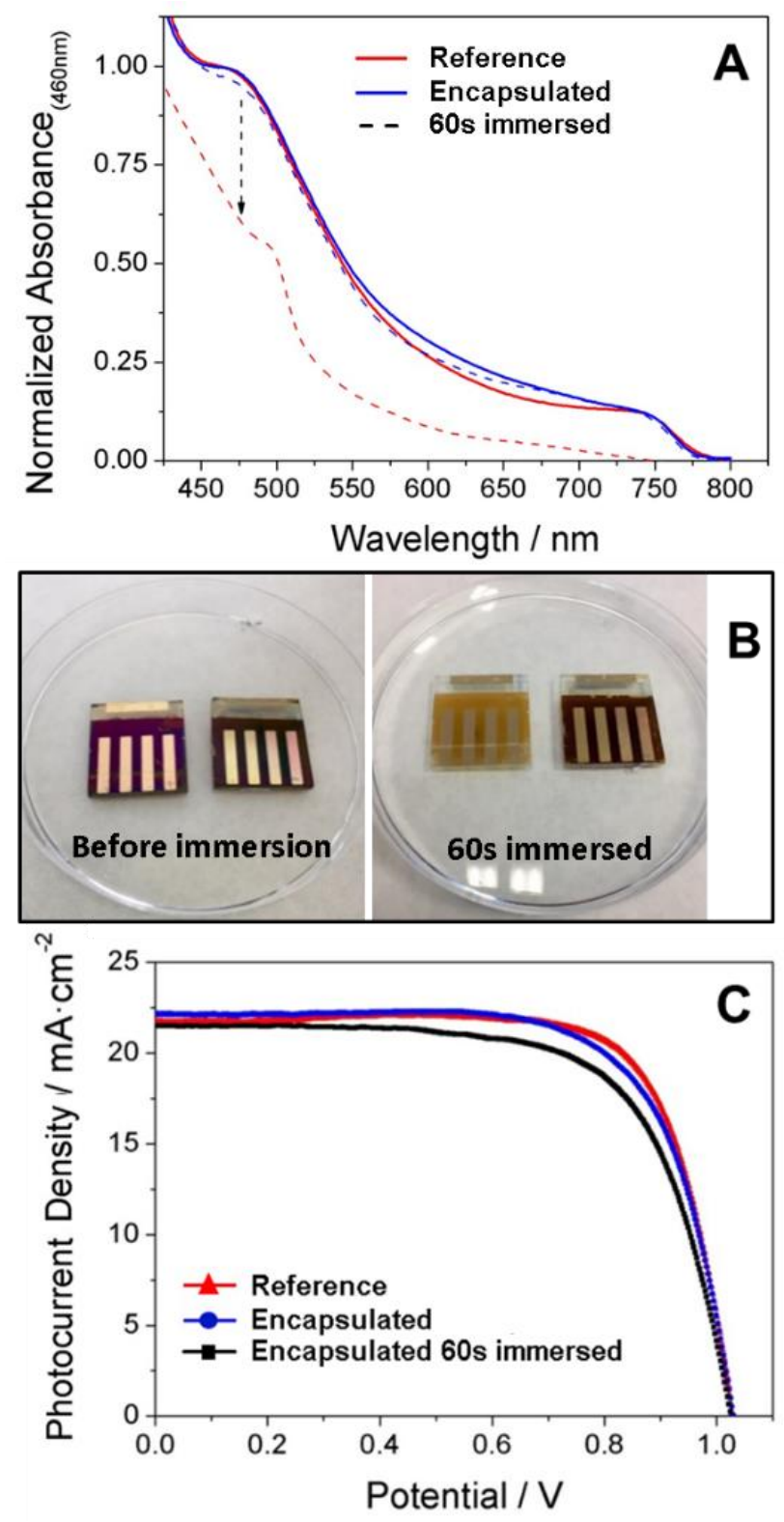

Figure 4. (A) UV-Vis spectra and (B) digital photographs of reference and encapsulated devices before and after an immersion in water of 60 seconds. (C) Photocurrent density-voltage curves for reference and encapsulated devices before the water immersion. Current-Voltage curves were performed under 1 sun AM 1.5 illumination in reverse scan with a scan rate of $100 \mathrm{mV} \cdot \mathrm{s}^{-1}$. 
Thus, considering the ability of ADA thin films as effective barrier layer to avoid the moistureinduced degradation of perovskite solar cells, we also investigated the water resistance of encapsulated devices. The immersion in water of reference devices produces the immediate dissolution of perovskite films (Figure 4A). Consequently, the reference devices suffer a color change from brown to yellow which does not only produce the decrease of the absorbance spectrum, but also the change of shape due to the formation of $\mathrm{PbI}_{2} \cdot{ }^{24}$ Similar spectra were observed in Figure 2A for the longest moisture exposure times for reference films. However, after 60 seconds immersed in water, encapsulated devices do not suffer from any apparent visual change. This is in line with the measured absorbance spectra before and after water immersion. To further confirm the blocking of water molecules diffusion through ADA thin film, the power conversion efficiency of encapsulated devices after 60 seconds immersed in water was also measured (Figure 4B). As it was shown above (Figure 1C), reference and encapsulated devices present the same photovoltaic parameters. Obviously, only the current-voltage curve for encapsulated devices could be measured after water immersion (Figure 4B). An average photovoltaic performance of $14.1 \%\left(J_{s c}: 20 \mathrm{~mA} \cdot \mathrm{cm}^{-2}, V_{o c}: 1020 \mathrm{mV}\right.$, Fill Factor: 0.69) was obtained under standard conditions (1 sun - AM 1.5 illumination). An efficiency drop of just 5\% with respect to the power conversion efficiency of devices before water immersion was detected. This efficiency drop has been mainly attributed to a small decay of fill factor which could be due to a possible water infiltration trough contact points or the edges of the devices. 

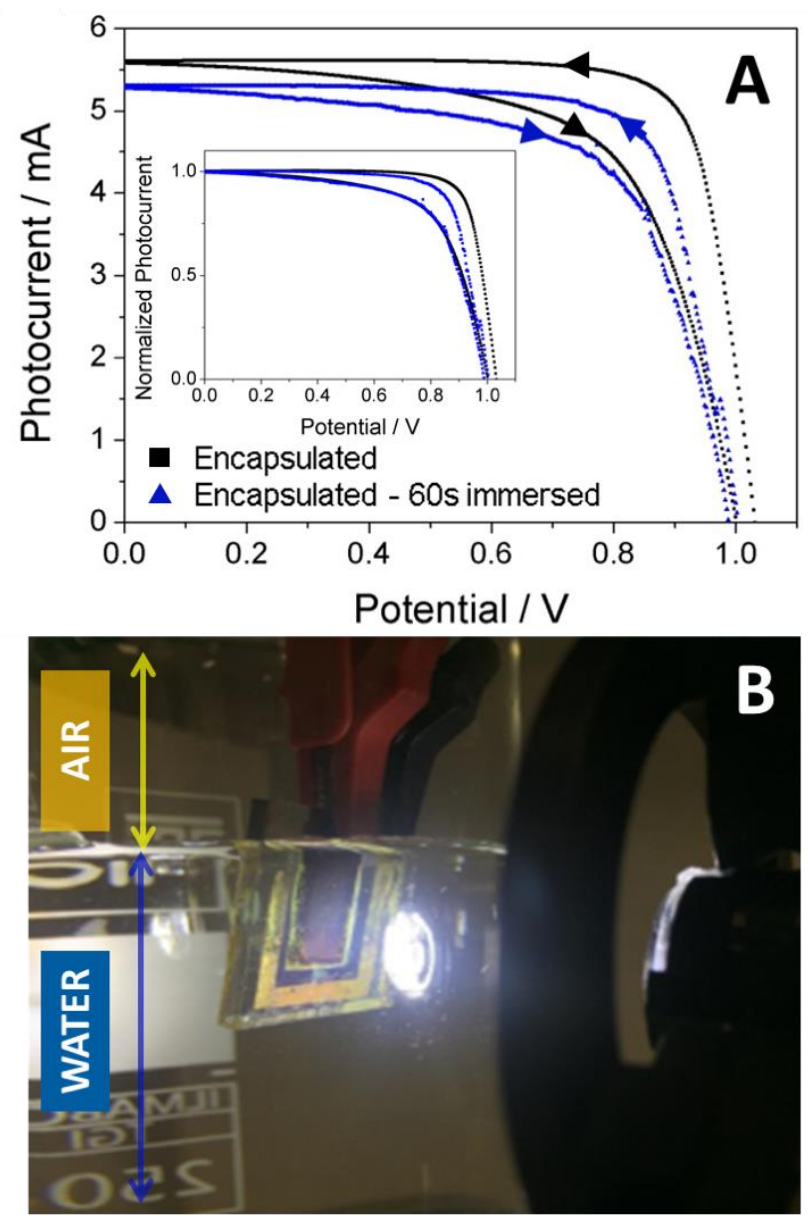

Figure 5. (A) Photocurrent-voltage curves for encapsulated devices performed in air and under water after 60 seconds as water immersion time. Photocurrent-voltage curves were performed using a whiteLED as illumination source in reverse and forward scans with a scan rate of $100 \mathrm{mV} \cdot \mathrm{s}^{-1}$. The inset shows the normalized photocurrent-voltage curve. (B) Digital photograph of encapsulated under water and illumination.

Finally, in relation to photoelectrochemical applications and a possible future use of perovskite devices for water splitting and production of $\mathrm{H}_{2}$ as energy source, ${ }^{42,43}$ the photovoltaic performance of encapsulated devices were measured under photovoltaic operation while immersed in water (Figure 5). The current-voltage curve was measured after 60 seconds under water showing only a small decrease of the short-circuit photocurrent and open-circuit 
photovoltage. The decrease of both photovoltaic parameters with respect to the ones measured before water immersion points to a reduction of light intensity as consequence of dispersion or reflation losses due to the water/glass interface. This assumption was corroborated by the normalization of the current-voltage curves by the short-circuit photocurrent. As shown the Inset of Figure 5A, no significant difference was observed between the current-voltage curves measured in air and under water. For longer immersion times water infiltration is observed through the edges of the devices. Since this can be easily solved by further design developments (work underway), the employment of ADA thin films as encapsulation method opens up a new possibility window for the use of perovskite devices in photoelectrocatalysis applications.

\section{Conclusions}

An effective encapsulation method of perovskites solar devices using an adamantane nanocomposite thin film deposited by remote plasma-assisted vacuum deposition method has been reported. This solvent-free polymer deposition technique allows for good electrical contact and does not affect negatively the photovoltaic parameters that determine the power energy conversion efficiency of the devices. An improvement of perovskite stability has been demonstrated not only under moisture exposure and even illumination, but also when devices where immersed under water. This deposition technique can be easily upscale to large deposition areas and is virtually independent of the composition of the cell elements. We envisage that the encapsulation methodology presented here will have a positive impact in the future development of stable and efficient cells, both in photovoltaics and water-splitting research. 


\section{AUTHOR INFORMATION}

\section{Corresponding Author}

E-mail: jaidileo@upo.es

E-mail: angel.barranco@csic.es

E-mail: anta@upo.es

\section{Author Contributions}

The manuscript was written through contributions of all authors. All authors have given approval to the final version of the manuscript.

\section{ACKNOWLEDGMENT}

We thank Junta de Andalucía for financial support via grant FQM 1851 and FQM 2310. We thank Ministerio de Economía y Competitividad of Spain and Agencia Estatal de Investigación (AEI) and EU (FEDER) under grants MAT2013-47192-C3-3-R, MAT2016-76892-C3-2-R, MAT2016-79866-R and Red de Excelencia "Emerging photovoltaic Technologies" for financial support. F.J. Aparicio acknowledges the Juan de la Cierva Program. J.R.S.-V. and Á.B. acknowledge the EU project PlasmaPerovSol. J.R.S.-V. and -Á.B. acknowledge funding from the European Union's Horizon 2020 research and innovation programme under the Marie Skłodowska-Curie grant agreement ID 661480. We also thank Servicio de Microscopía Electrónica (Universidad Pablo de Olavide). 


\section{REFERENCES}

(1) Xing, G.; Mathews, N.; Sun, S.; Lim, S. S.; Lam, Y. M.; Grätzel, M.; Mhaisalkar, S.; Sum, T. C. Long-Range Balanced Electron- and Hole-Transport Lengths in Organic-Inorganic CH3NH3PbI3. Science 2013, 342 (6156), 344-347.

(2) Stranks, S. D.; Eperon, G. E.; Grancini, G.; Menelaou, C.; Alcocer, M. J. P.; Leijtens, T.; Herz, L. M.; Petrozza, A.; Snaith, H. J. Electron-Hole Diffusion Lengths Exceeding 1 Micrometer in an Organometal Trihalide Perovskite Absorber. Science 2013, 342 (6156), 341-344.

(3) Tress, W.; Marinova, N.; Inganäs, O.; Nazeeruddin, M. K.; Zakeeruddin, S. M.; Graetzel, M. Predicting the Open-Circuit Voltage of CH3NH3PbI3 Perovskite Solar Cells Using Electroluminescence and Photovoltaic Quantum Efficiency Spectra: The Role of Radiative and Non-Radiative Recombination. Adv. Energy Mater. 2015, 5 (3), 1400812-1400818.

(4) Pellet, N.; Gao, P.; Gregori, G.; Yang, T.-Y.; Nazeeruddin, M. K.; Maier, J.; Grätzel, M. Mixed-Organic-Cation Perovskite Photovoltaics for Enhanced Solar-Light Harvesting. Angew. Chem. Int. Ed. 2014, 53 (12), 3151-3157.

(5) Kojima, A.; Teshima, K.; Shirai, Y.; Miyasaka, T. Organometal Halide Perovskites as Visible-Light Sensitizers for Photovoltaic Cells. J. Am. Chem. Soc. 2009, 131 (17), 60506051.

(6) Lee, M. M.; Teuscher, J.; Miyasaka, T.; Murakami, T. N.; Snaith, H. J. Efficient Hybrid Solar Cells Based on Meso-Superstructured Organometal Halide Perovskites. Science 2012, 338 (6107), 643.

(7) Kim, H.-S.; Lee, C.-R.; Im, J.-H.; Lee, K.-B.; Moehl, T.; Marchioro, A.; Moon, S.-J.; Humphry-Baker, R.; Yum, J.-H.; Moser, J. E.; Grätzel, M.; Park, N.-G. Lead Iodide Perovskite Sensitized All-Solid-State Submicron Thin Film Mesoscopic Solar Cell with Efficiency Exceeding 9\%. Sci. Rep. 2012, 2, 591.

(8) Photovoltaic Research | NREL https://www.nrel.gov/pv/ (accessed Feb 10, 2017).

(9) Saliba, M.; Matsui, T.; Seo, J.-Y.; Domanski, K.; Correa-Baena, J.-P.; Nazeeruddin, M. K.; Zakeeruddin, S. M.; Tress, W.; Abate, A.; Hagfeldt, A.; Gratzel, M. CesiumContaining Triple Cation Perovskite Solar Cells: Improved Stability, Reproducibility and High Efficiency. Energy Environ. Sci. 2016, 9 (6), 1989-1997.

(10) Sutton, R. J.; Eperon, G. E.; Miranda, L.; Parrott, E. S.; Kamino, B. A.; Patel, J. B.; Hörantner, M. T.; Johnston, M. B.; Haghighirad, A. A.; Moore, D. T.; Snaith, H. J. Bandgap-Tunable Cesium Lead Halide Perovskites with High Thermal Stability for Efficient Solar Cells. Adv. Energy Mater. 2016, 6 (8), 1502458-1502464.

(11) Li, B.; Li, Y.; Zheng, C.; Gao, D.; Huang, W. Advancements in the Stability of Perovskite Solar Cells: Degradation Mechanisms and Improvement Approaches. RSC Adv. 2016, 6 (44), 38079-38091.

(12) Berhe, T. A.; Su, W.-N.; Chen, C.-H.; Pan, C.-J.; Cheng, J.-H.; Chen, H.-M.; Tsai, M.-C.; Chen, L.-Y.; Dubale, A. A.; Hwang, B.-J. Organometal Halide Perovskite Solar Cells: Degradation and Stability. Energy Environ. Sci. 2016, 9 (2), 323-356.

(13) Leguy, A. M. A.; Hu, Y.; Campoy-Quiles, M.; Alonso, M. I.; Weber, O. J.; Azarhoosh, P.; van Schilfgaarde, M.; Weller, M. T.; Bein, T.; Nelson, J.; Docampo, P.; Barnes, P. R. F. 
Reversible Hydration of CH3NH3PbI3 in Films, Single Crystals, and Solar Cells. Chem. Mater. 2015, 27 (9), 3397-3407.

(14) Salado, M.; Contreras-Bernal, L.; Calio, L.; Todinova, A.; Lopez-Santos, C.; Ahmad, S.; Borras, A.; Idigoras, J.; Anta, J. A. Impact of Moisture on Efficiency-Determining Electronic Processes in Perovskite Solar Cells. J. Mater. Chem. A 2017, 5 (22), 1091710927.

(15) Christians, J. A.; Miranda Herrera, P. A.; Kamat, P. V. Transformation of the Excited State and Photovoltaic Efficiency of $\mathrm{CH} 3 \mathrm{NH} 3 \mathrm{PbI} 3$ Perovskite upon Controlled Exposure to Humidified Air. J. Am. Chem. Soc. 2015, 137 (4), 1530-1538.

(16) Sun, Y.; Wu, Y.; Fang, X.; Xu, L.; Ma, Z.; Lu, Y.; Zhang, W.-H.; Yu, Q.; Yuan, N.; Ding, J. Long-Term Stability of Organic-Inorganic Hybrid Perovskite Solar Cells with High Efficiency under High Humidity Conditions. J. Mater. Chem. A 2017, 5 (4), 1374-1379.

(17) Guarnera, S.; Abate, A.; Zhang, W.; Foster, J. M.; Richardson, G.; Petrozza, A.; Snaith, H. J. Improving the Long-Term Stability of Perovskite Solar Cells with a Porous A12O3 Buffer Layer. J. Phys. Chem. Lett. 2015, 6 (3), 432-437.

(18) Koushik, D.; Verhees, W. J. H.; Kuang, Y.; Veenstra, S.; Zhang, D.; Verheijen, M. A.; Creatore, M.; Schropp, R. E. I. High-Efficiency Humidity-Stable Planar Perovskite Solar Cells Based on Atomic Layer Architecture. Energy Environ. Sci. 2017, 10 (1), 91-100.

(19) Dong, X.; Fang, X.; Lv, M.; Lin, B.; Zhang, S.; Ding, J.; Yuan, N. Improvement of the Humidity Stability of Organic-Inorganic Perovskite Solar Cells Using Ultrathin A12O3 Layers Prepared by Atomic Layer Deposition. J. Mater. Chem. A 2015, 3 (10), 53605367.

(20) Zheng, L.; Chung, Y.-H.; Ma, Y.; Zhang, L.; Xiao, L.; Chen, Z.; Wang, S.; Qu, B.; Gong, Q. A Hydrophobic Hole Transporting Oligothiophene for Planar Perovskite Solar Cells with Improved Stability. Chem. Commun. 2014, 50 (76), 11196-11199.

(21) Kwon, Y. S.; Lim, J.; Yun, H.-J.; Kim, Y.-H.; Park, T. A Diketopyrrolopyrrole-Containing Hole Transporting Conjugated Polymer for Use in Efficient Stable Organic-Inorganic Hybrid Solar Cells Based on a Perovskite. Energy Environ. Sci. 2014, 7 (4), 1454-1460.

(22) Wei, Z.; Zheng, X.; Chen, H.; Long, X.; Wang, Z.; Yang, S. A Multifunctional C + Epoxy/Ag-Paint Cathode Enables Efficient and Stable Operation of Perovskite Solar Cells in Watery Environments. J. Mater. Chem. A 2015, 3 (32), 16430-16434.

(23) Habisreutinger, S. N.; Leijtens, T.; Eperon, G. E.; Stranks, S. D.; Nicholas, R. J.; Snaith, H. J. Carbon Nanotube/Polymer Composites as a Highly Stable Hole Collection Layer in Perovskite Solar Cells. Nano Lett. 2014, 14 (10), 5561-5568.

(24) Hwang, I.; Jeong, I.; Lee, J.; Ko, M. J.; Yong, K. Enhancing Stability of Perovskite Solar Cells to Moisture by the Facile Hydrophobic Passivation. ACS Appl. Mater. Interfaces 2015, 7 (31), 17330-17336.

(25) Chang, C.-Y.; Lee, K.-T.; Huang, W.-K.; Siao, H.-Y.; Chang, Y.-C. High-Performance, Air-Stable, Low-Temperature Processed Semitransparent Perovskite Solar Cells Enabled by Atomic Layer Deposition. Chem. Mater. 2015, 27 (14), 5122-5130.

(26) Tan, L.; Liu, C.; Huang, Z.; Zhang, Y.; Chen, L.; Chen, Y. Self-Encapsulated SemiTransparent Perovskite Solar Cells with Water-Soaked Stability and Metal-Free Electrode. Org. Electron. 2017, 48, 308-313.

(27) Grancini, G.; Roldán-Carmona, C.; Zimmermann, I.; Mosconi, E.; Lee, X.; Martineau, D.; Narbey, S.; Oswald, F.; De Angelis, F.; Graetzel, M.; Nazeeruddin, M. K. One-Year 
Stable Perovskite Solar Cells by 2D/3D Interface Engineering. Nature Communications 2017, 8, 15684.

(28) Blaszczyk-Lezak, I.; Aparicio, F. J.; Borrás, A.; Barranco, A.; Álvarez-Herrero, A.; Fernández-Rodríguez, M.; González-Elipe, A. R. Optically Active Luminescent Perylene Thin Films Deposited by Plasma Polymerization. J. Phys. Chem. C 2009, 113 (1), $431-$ 438.

(29) Aparicio, F. J.; Alcaire, M.; Borras, A.; Gonzalez, J. C.; Lopez-Arbeloa, F.; BlaszczykLezak, I.; Gonzalez-Elipe, A. R.; Barranco, A. Luminescent 3-Hydroxyflavone Nanocomposites with a Tuneable Refractive Index for Photonics and UV Detection by Plasma Assisted Vacuum Deposition. J. Mater. Chem. C 2014, 2 (32), 6561-6573.

(30) Alcaire, M.; Cerdán, L.; Zamarro, F. L.; Aparicio, F. J.; González, J. C.; Ferrer, F. J.; Borras, A.; Espinós, J. P.; Barranco, A. Multicolored Emission and Lasing in DCMAdamantane Plasma Nanocomposite Optical Films. ACS Appl. Mater. Interfaces 2017, 9 (10), 8948-8959.

(31) Filippin, A. N.; Sanchez-Valencia, J. R.; Idígoras, J.; Macias-Montero, M.; Alcaire, M.; Aparicio, F. J.; Espinos, J. P.; Lopez-Santos, C.; Frutos, F.; Barranco, A.; Anta, J. A.; Borras, A. Low-Temperature Plasma Processing of Platinum Porphyrins for the Development of Metal Nanostructured Layers. Adv. Mater. Interfaces 2017, 4 (14), $1601233-1601245$.

(32) Aparicio, F. J.; Holgado, M.; Borras, A.; Blaszczyk-Lezak, I.; Griol, A.; Barrios, C. A.; Casquel, R.; Sanza, F. J.; Sohlström, H.; Antelius, M.; González-Elipe, A. R.; Barranco, A. Transparent Nanometric Organic Luminescent Films as UV-Active Components in Photonic Structures. Adv. Mater. 2011, 23 (6), 761-765.

(33) Aparicio, F. J.; Alcaire, M.; González-Elipe, A. R.; Barranco, A.; Holgado, M.; Casquel, R.; Sanza, F. J.; Griol, A.; Bernier, D.; Dortu, F.; Cáceres, S.; Antelius, M.; Lapisa, M.; Sohlström, H.; Niklaus, F. Dye-Based Photonic Sensing Systems. Sens. Actuators B Chem. 2016, 228 (Supplement C), 649-657.

(34) Aparicio, F. J.; Blaszczyk-Lezak, I.; Sánchez-Valencia, J. R.; Alcaire, M.; González, J. C.; Serra, C.; González-Elipe, A. R.; Barranco, A. Plasma Deposition of PeryleneAdamantane Nanocomposite Thin Films for NO2 Room-Temperature Optical Sensing. $J$. Phys. Chem. C 2012, $116(15), 8731-8740$.

(35) Aranda, C.; Cristobal, C.; Shooshtari, L.; Li, C.; Huettner, S.; Guerrero, A. Formation Criteria of High Efficiency Perovskite Solar Cells under Ambient Conditions. Sustain. Energy Fuels 2017, 1 (3), 540-547.

(36) Barranco, A.; Aparicio, F.; Yanguas-Gil, A.; Groening, P.; Cotrino, J.; González-Elipe, A. R. Optically Active Thin Films Deposited by Plasma Polymerization of Dye Molecules. Chem. Vap. Depos. 2007, 13 (6-7), 319-325.

(37) Terriza, A.; Álvarez, R.; Borrás, A.; Cotrino, J.; Yubero, F.; González-Elipe, A. R. Roughness Assessment and Wetting Behavior of Fluorocarbon Surfaces. J. Colloid Interface Sci. 2012, 376 (1), 274-282.

(38) Yang, J.; Siempelkamp, B. D.; Liu, D.; Kelly, T. L. Investigation of CH3NH3PbI3 Degradation Rates and Mechanisms in Controlled Humidity Environments Using in Situ Techniques. ACS Nano 2015, 9 (2), 1955-1963.

(39) Bryant, D.; Aristidou, N.; Pont, S.; Sanchez-Molina, I.; Chotchunangatchaval, T.; Wheeler, S.; Durrant, J. R.; Haque, S. A. Light and Oxygen Induced Degradation Limits 
the Operational Stability of Methylammonium Lead Triiodide Perovskite Solar Cells. Energy Environ. Sci. 2016, 9 (5), 1655-1660.

(40) Chen, Q.; Zhou, H.; Song, T.-B.; Luo, S.; Hong, Z.; Duan, H.-S.; Dou, L.; Liu, Y.; Yang, Y. Controllable Self-Induced Passivation of Hybrid Lead Iodide Perovskites toward High Performance Solar Cells. Nano Lett. 2014, 14 (7), 4158-4163.

(41) Guo, X.; McCleese, C.; Kolodziej, C.; Samia, A. C. S.; Zhao, Y.; Burda, C. Identification and Characterization of the Intermediate Phase in Hybrid Organic-Inorganic MAPbI3 Perovskite. Dalton Trans. 2016, 45 (9), 3806-3813.

(42) Chen, Y.-S.; Manser, J. S.; Kamat, P. V. All Solution-Processed Lead Halide PerovskiteBiVO4 Tandem Assembly for Photolytic Solar Fuels Production. J. Am. Chem. Soc. 2015, 137 (2), 974-981.

(43) Hoang, M. T.; Pham, N. D.; Han, J. H.; Gardner, J. M.; Oh, I. Integrated Photoelectrolysis of Water Implemented On Organic Metal Halide Perovskite Photoelectrode. ACS Appl. Mater. Interfaces 2016, 8 (19), 11904-11909. 